\title{
A Letter from the TMS President: What Does TMS Membership Say about You?
}

\author{
Wolfgang Schneider
}

How do you define yourself professionally? As a scientist? An engineer? An academic? A researcher? A young professional? A retiree? As someone who wants to change the world?

I think of myself as a TMS member, because it encompasses all of these aspects of a materials professional's identity. TMS membership signifies a commitment to your work and your field. It shows that you take your career seriously, that you care about your profession, and that you want to use your talents to benefit society. It shows that you are part of an organization with a distinguished history and a bright future.

TMS recently unveiled an ambitious strategic plan that will benefit all TMS members, no matter how you define yourself:

- For young professionals: TMS is tripling the size of its Young Leader program, offering more leadership development and travel opportunities for the future leaders of MSE.

- For volunteers: To improve services to our volunteer membersand to thank them for their numerous contributions to the societyTMS is developing programs that provide professional development training exclusively for volunteer members and that encourage diversity in society leadership.

- For those working in emerging technologies: TMS will broaden its engagement in two specific areas: 1) materials solutions for energy and environmental challenges and 2) materials and manufacturing innovation. TMS is providing conference venues, publication outlets, and on-line resources and partnering with government agencies to advance the profile of these fields.

- For those working in core technologies: Strengthening offerings and opportunities in the core technology areas in which many TMS members work is another key goal of the strategic plan. The society is closely examining its technical structure and identifying new ways to grow in traditional technology areas.

As we embark on these new goals, we invite you to share your ideas and to volunteer your expertise. But most of all, we invite you to benefit from your involvement with the society, whether as an active contributor or as someone who accesses our vast resources to further your own work. In addition to the benefits listed above, TMS members always have access to:

- JOM: The signature society journal delivers news, research, and insights to members every month, both in print and on-line. With its impact factor rising in recent years, JOM's influence in the materials community continues to grow.

- Additional Journals: Members receive on-line subscriptions to Metallurgical and Materials Transactions $A$ and B, Journal of Electronic Materials, and 20 additional materials journals, as well as easy access to the society's new journal, Integrating Materials and Manufacturing Innovation.

- Job Search and Professional Development Resources: Access job-search tools, consult career- development experts and mentors, and find qualified employees through TMS's Career Resources.

- Discounts on Meetings and Books: TMS membership pays for itself in discounts on registration for the TMS Annual Meeting, Materials Science \& Technology (MS\&T), or any of the specialty conferences the society holds each year. Members can also purchase discounted conference proceedings, textbooks, and compilations.

- Technical Committee Membership: Members can build a network of colleagues, shape TMS meeting programming, gain valuable professional skills, and enhance their resumes by volunteering with a technical committee.

- Professional Education: One of my goals as TMS president is to expand and improve TMS's continuing education program, so expect more diverse offerings of short courses, tutorials, specialty conferences, and workshops in the coming year.

I have been a TMS member-and an active participant in the society-for 16 years, and my membership has helped to define me as a professional. When you receive a message asking you to renew your membership for 2013, I encourage you to do so immediately to ensure that you, too, will benefit from all of TMS's exciting, new initiatives and vast resources.

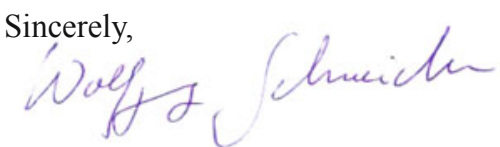

Wolfgang Schneider

TMS 2012 President 